\title{
Performance Comparison of Coagulation, Ultrafiltration and Combined Coagulation and Ultrafiltration for Water Reclamation
}

\author{
J. Yimratanabovorn, W. Wonglertarak, O. Rungrueang, C. Hirunteeyakul, and B. Wichitsathein
}

\begin{abstract}
Reclaimed water offers prospects as an alternative water resource. Many technologies have been developed to treat reclaimed wastewater technologies. The membrane technology is considered one of the most effective water treatment technologies for water reclamation. Ultrafiltration membranes are particularly effective at removing microorganisms in wastewater, particularly protozoa. Coagulation-flocculation is a feasible process to reclaim water and widely used as a pre-treatment. The aim of this study is to investigate the performance of water reclamations processes: the single coagulation-flocculation, the single ultrafiltration and the combined coagulation-flocculation and ultrafiltration. The pilot scale laboratories of each process was operated and have been characterized in order to evaluate the performance. The results of combined $\mathrm{CF}+\mathrm{UF}$ process had the highest performance of $\mathrm{COD}$, turbidity and color removal efficiencies than the single $\mathrm{CF}$ process and the single UF process. The combination of $\mathrm{CF}+\mathrm{UF}$ helps to improve the process performance and enhanced COD, turbidity and color removal efficiencies of combined processes. The reclaimed water from combined $\mathrm{CF}+\mathrm{UF}$ process can be used for vehicle washing, urban landscaping and toilet flushing purposes. In addition, can be used as water supply. However, to use instead of water supply should be evaluated the bacteria indicators, hygienic safety and economic feasibility.
\end{abstract}

Index Terms-Reclaimed water, ultrafiltration, coagulation-flocculation.

\section{INTRODUCTION}

Reclaiming and reusing wastewater has been implemented as an important strategy to ensure sustainable development and alleviate water shortage. Even though reclaimed wastewater has been a stable source of water supplies but in fact, reclaimed wastewater cannot be substituted for the diverse applications of water, mainly because of the difficulty to complete satisfy the supplied water quality standards. There is no doubt that effective and efficient wastewater reclamation process will be one important consideration. Many technologies have been developed to treat reclaimed wastewater technologies to fulfill the satisfying water user. Reclaimed wastewater should fulfill following criteria: hygienic safety, aesthetics, environmental tolerance and technical and economic feasibility [1]. The membrane technology is considered one of the most effective water

Manuscript received April 12, 2018; revised June 26, 2018.

The authors are with Suranaree University of Technology, Nakhon Ratchasima, 30000, Thailand (e-mail: chareeya@sut.ac.th, w_watcharapol@hotmail.com, oraneerr@gmail.com, boonchai@sut.ac.th, chow@sut.ac.th). treatment technology for water reclamation because it is able to tally remove various contaminants, including bacteria, suspended solids, and organic particle bigger than the pore size, however, there are restrictions that arise because of high capital, exploitation cost and membrane fouling [2], [3]. Ultrafiltration membranes (UF) are particularly effective at removing microorganisms in wastewater, particularly protozoa such as Cryptosporidium and bacteria such as Escherichia coli [4]. Coagulation-flocculation is a feasible process to reclaim municipal wastewater and widely used as a pre-treatment. Moreover, coagulation is the most commonly employed advanced wastewater treatment process for economic reasons [5]. The aim of this study is to investigate the performance of water reclamations processes: the single coagulation-flocculation, the single ultrafiltration and the combined coagulation-flocculation and ultrafiltration. The pilot scale laboratories of each process was operated and have been characterized in order to evaluate the performance. In addition, the water quality of each process has been considered for varied purposes such as toilet flushing, car wash, agricultural irrigation and water supply.

\section{MATERIALS AND METHOD}

The study was carried out to reclaim effluent from wastewater treatment system of Suranaree University of Technology, Nakhonratchasima province, Thailand.

\section{A. The Pilot-Scale Water Reclamation Plants}

The three alternatives of water reclamation processes were set as pilot scale in laboratory; 1) single coagulation-flocculation (CF) 2) single Ultrafiltration (UF) and 3) combined coagulation-flocculation and Ultrafiltration $(\mathrm{CF}+\mathrm{UF})$. Schematic of three alternatives were shown in Fig. 1,2 and 3 respectively.

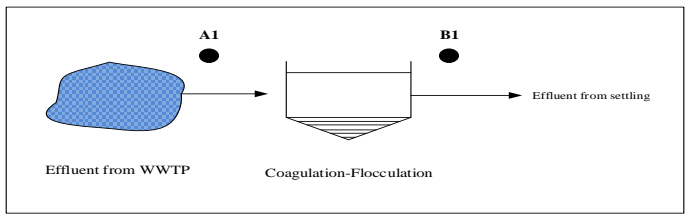

Fig. 1. Schematic of alternatives I single coagulation-flocculation process (CF).

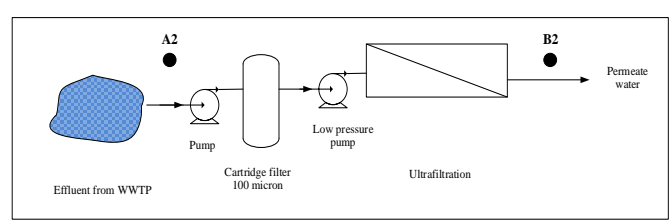

Fig. 2. Schematic of alternative II single ultrafiltration process (UF). 


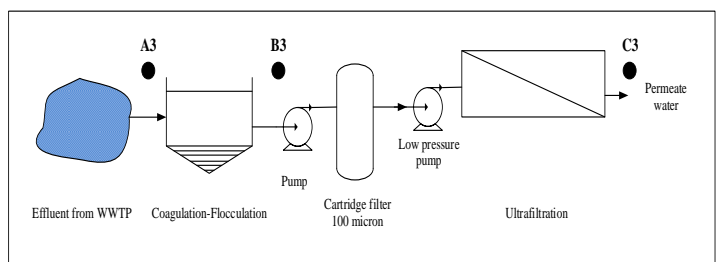

Fig. 3. Schematic of alternative III combined coagulation-flocculation and ultrafiltration process $(\mathrm{CF}+\mathrm{UF})$.

\section{B. The Pilot-Scale of Single CF Process}

The coagulation-flocculation studies were carried out using the jar test method to determine the optimum $\mathrm{pH}$ range, suitable dose of polyaluminium chloride $\left(\mathrm{Al}_{2}(\mathrm{OH})_{3} \mathrm{Cl}_{3}\right)$ or $\mathrm{PAC}$ and polymer for each sampling wastewater.

\section{The Performance of Single CF Laboratory Scale}

The coagulation studies were carried out by use the optimum $\mathrm{pH}$ range, volume of $\mathrm{PAC}$ and polymer from chemical of coagulation study. Water samples were collected at point A1 and B1 to calculate removal efficiencies by using Eq. (1).

$$
\% \text { Removal Efficiency }=\frac{\left(C_{0}-C_{e}\right)}{C_{0}} \times 100
$$

\section{The Pilot-Scale of Single UF Laboratory Scale}

In this study, the UF process was operated at permeate flux $80 \mathrm{~L} / \mathrm{m} 2 . \mathrm{hr}$ and ratio of permeate and retentate was 25:75. Water samples were collected at A2 and B2 to calculate removal efficiencies by using Eq. (1).

\section{E. The Pilot-Scale of Combined CF $+U F$ Laboratory Scale}

The wastewater was feed to combined $\mathrm{CF}+\mathrm{UF}$ pilot scale and water samples were collected at A3 B3 and C3 to calculate removal efficiencies by using Eq. (1).

\section{F. Water Sampling}

Water samples were analyzed for various parameters by analytical methods as shown in Table I.

\section{TABLE I: PARAMETER AND ANALYTICAL METHODS}

\begin{tabular}{ll}
\hline Parameters & Analytical methods \\
\hline Physical and Chemical quality \\
Turbidity & 2130 B. Nephelometric Method \\
Color & 2120 D. Spectrophotometric Method \\
BOD & 5210 B. 5-day BOD Test Method \\
Iron & 3500-Fe B. Phenanthroline Method \\
Manganese & 3500-Mn B. Persulfate Method \\
TSS & 2540 D. Gravimetric Method \\
TDS & 2540 C. Gravimetric Method \\
\hline
\end{tabular}

\section{RESULTS AND DISCUSSION}

The influent of water reclamation pilot scales that were taken from effluent of wastewater treatment system (WWS) of SUT, were characterized during the experiment and the values indicate that the influent correspond to the typical low COD and turbidity as can be shown in Table II.

\section{A. The Optimal Conditions for Coagulation-Flocculation Test}

The results of jar test were carried out to determine the chemicals and optimum $\mathrm{pH}$ for coagulation-flocculation process. They were found the optimum $\mathrm{pH}$ were in range of 6.5-8.5 and the volume of PAC and polymer were $3.41 \mathrm{ml} / \mathrm{L}$ and $1.45 \mathrm{ml} / \mathrm{L}$ respectively.

TABLE II: THE INFLUENT CHARACTERISTICS OF WATER RECLAMATION LABORATORY SCALES

\begin{tabular}{cccc}
\hline Parameter & Unit & Min-Max & Mean \pm SD \\
\hline COD & mg/L & $17.40-41.50$ & $28.99 \pm 7.99$ \\
Color & Pt-Co & $63-134$ & $98 \pm 23.71$ \\
Turbidity & NTU & $1.83-8.90$ & $5.34 \pm 1.91$ \\
TSS & mg/L & $19.00-58.67$ & $36.81 \pm 16.04$ \\
TDS & mg/L & $278.67-593.33$ & $399.19 \pm 89.91$ \\
pH & - & $7.2-9.1$ & $7.74 \pm 0.54$ \\
\hline
\end{tabular}

\section{B. The Performance of Single Coagulation-Flocculation (CF)}

The results of optimum conditions for single coagulation process as summarized in A were carried out to treated effluent from WWS of SUT for measuring the performance of $\mathrm{CF}$ process. The water samples before and after treated by $\mathrm{CF}$ process were analyzed and calculated the removal efficiencies. The results of COD turbidity and color removal efficiencies of coagulation process were presented in Fig. 4. They showed CF process had COD, turbidity and color removal efficiencies were in range of 30-75 \%, 55.94-85.53\% and 52.76-91.0\% respectively. The results indicated that $\mathrm{CF}$ had good removal efficiencies for all parameters over than $50 \%$.

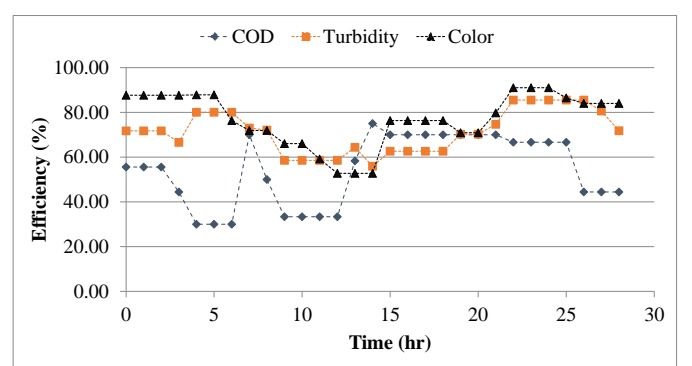

Fig. 4. The performance of single coagulation-flocculation pilot scale in COD, turbidity and color removal efficiencies.

\section{The Performance of Single Ultrafiltration Process (UF)}

The water samples before and after treated by UF process were analysed and calculated the removal efficiencies. The water samples before and after treated by UF process were analysed and calculated the removal efficiencies. The results of COD turbidity and color removal efficiencies of coagulation process were presented in Fig. 5. They showed UF process had COD, turbidity and color removal efficiencies were in range of $13.33-62.50 \%, 16.60-65.60 \%$ and 8.08-43.02\% respectively. The results indicated that $\mathrm{CF}$ process were not good removal efficiencies especially for color.

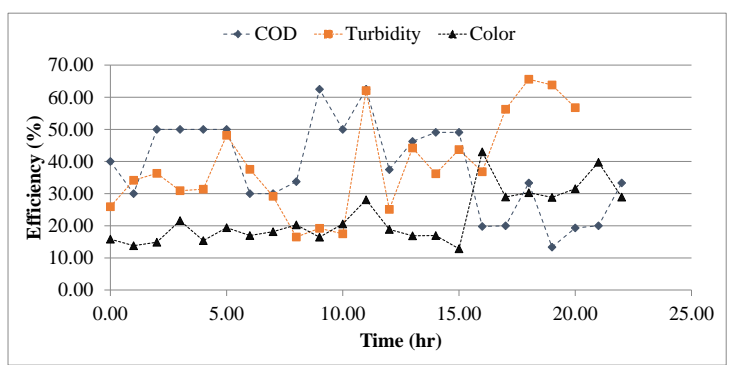

Fig. 5. The performance of ultrafiltration process (UF) laboratory scale in COD, turbidity and color removal efficiencies. 


\section{The Performance of Combined \\ Coagulation-Flocculation and Ultrafiltration Process $(C F+U F)$}

The water samples before and after treated by $\mathrm{CF}+\mathrm{UF}$ process were analysed and calculated the removal efficiencies The water samples before and after treated by $\mathrm{CF}+\mathrm{UF}$ process were analysed and calculated the removal efficiencies. The results of COD turbidity and color removal efficiencies of coagulation process were presented in Fig. 6. They showed $\mathrm{CF}+\mathrm{UF}$ process had $\mathrm{COD}$, turbidity and color removal efficiencies were in range of 30.0-80.0\%, 60.69-92.19\% and $68.80-92.50 \%$ respectively. The results indicated that $\mathrm{CF}+\mathrm{UF}$ had high removal efficiencies for all parameters.

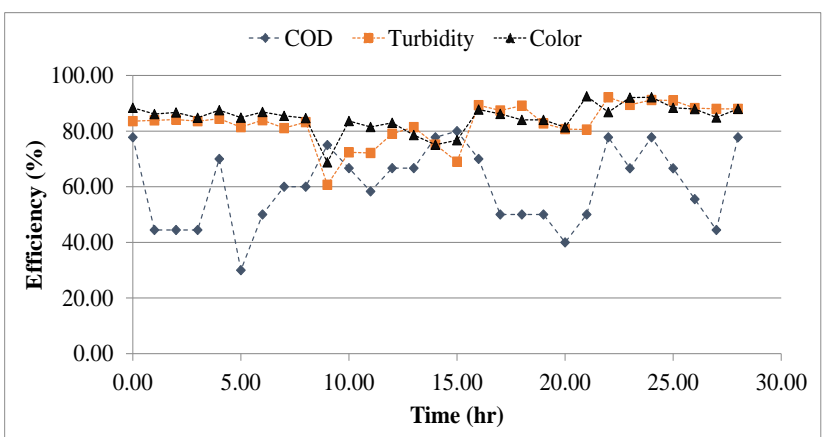

Fig. 6. The performance of combined coagulation-flocculation and ultrafiltration laboratory scale $(\mathrm{CF}+\mathrm{UF})$ in $\mathrm{COD}$, turbidity and color removal efficiencies.

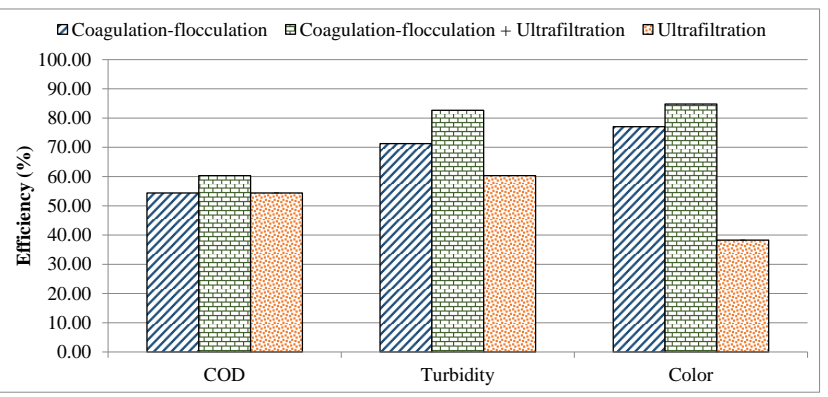

Fig. 7. Comparison performance of three alternatives water reclamation processes.

\section{E. Comparison Performance of Three Alternatives Water Reclamation Processes}

The performance of COD, turbidity and color removal efficiencies for three alternatives water reclamation processes are presented in Fig. 7. The results showed the combined $\mathrm{CF}+\mathrm{UF}$ processes had the overall $\mathrm{COD}$, turbidity and color removal efficiencies higher than the $\mathrm{CF}$ process and UF process. These results indicated that combination of two processes help to improve the process performance and adding coagulation process as pre-treatment for ultrafiltration enhanced COD, turbidity and color removal efficiencies of combined processes. These results probably because pollutants was adsorbed on or trapped in the aluminium floc particles, which were trapped by UF [6]. Water qualities of effluents from each process were assessed to utilize purposes by using water quality standard as shown in [7]. In previous study [8], found that combined ozonation, coagulation and membrane filtration process improved operational performance and produced reclaimed water with reduce public health risks associated with virus and $\mathrm{N}$-nitrosodimethylamine. The results showed the reclaimed water of single $\mathrm{CF}$ and combined $\mathrm{CF}+\mathrm{UF}$ process can be used for vehicle washing, urban landscaping and toilet flushing purposes. Moreover, the reclaimed water of combined $\mathrm{CF}+\mathrm{UF}$ process can be used as water supply. The other hand, the reclaimed water of single UF can be used as road sweeping and construction purposes.

Acceptance of the use of recycled water for other uses and applications, such as food crop irrigation and watering of residential lawns may increase as public knowledge and general understanding of the associate benefits of water reuse [9]. However, the public risk perceptions and trust have been shown to be important key factors in acceptance of potable recycled water [10].

\section{CONCLUSIONS}

The combined $\mathrm{CF}+\mathrm{UF}$ process had the highest performance of COD, turbidity and color removal efficiencies than the single $\mathrm{CF}$ process and the single UF process. The combination of $\mathrm{CF}+\mathrm{UF}$ helps to improve the process performance and enhanced COD, turbidity and color removal efficiencies of combined processes. The reclaimed water from combined $\mathrm{CF}+\mathrm{UF}$ process can be used for vehicle washing, urban landscaping and toilet flushing purposes. In addition, can be used as water supply. However, to use instead of water supply should be evaluated the bacteria indicators, hygienic safety and economic feasibility.

\section{ACKNOWLEDGEMENTS}

This study was supported by Suranaree University of Technology and Thailand Institute of Scientific and Technological Research

\section{REFERENCES}

[1] H. Al-Hamaiedeh and M. Bino, "Effect of treated grey water reuse in irrigation on soil andplants," Desalination, pp. 115-119, vol. 256, 2010.

[2] C. Jarusutthirak, G. Amy, and J. P. Croué, "Fouling characteristics of wastewater effluent organic matter (EfOM) isolates on NF and UF membranes," Desalination, pp. 247-255, vol. 145, 2002.

[3] H. K. Shon, S. I. Vigneswaran, S. Kim, J. Cho, and H. H. Ngo, "Fouling of ultrafiltration membrane by effluent organic matter: A detailed characterization using different organic fractions in wastewater," J. Membr. Sci., pp. 232-238, vol. 278, 2006.

[4] O. Ferrer, S. Casas, C. Galva-n, F. Lucena, A. Bosch, B. Galofr, J. Mesa, J. Jofre, and X. Bernat, "Direct ultrafiltration performance and membrane integrity monitoring by microbiological analysis," Water Res, pp. 121-131, vol. 83, 2015.

[5] C. Xiaochun, Z. Dandan, F. Wei, H. Mingxin, C. John, C. Crittenden, Y. Zhisen, J. Pengfei, and W. Yang, "The effectiveness of coagulation for water reclamation from a wastewater treatment plant that has a long hydraulic and sludge retention times: A case study," Chemosphere, pp. 224-231, vol. 157, 2016.

[6] S. Lee, M. Ihara, N. Yamashita, and H. Tanaka, "Improvement of virus removal by pilot-scale coagulation-ultrafiltration process for wastewater reclamation: Effect of optimization of $\mathrm{pH}$ in secondary effluent," Water Research, pp. 23-30, vol. 114, 2017.

[7] S. Rodrigues, "China reclaimed water reuse regulations," International Water Association, United Kingdom, 2002.

[8] D. Im, N. Nakada, Y. Fukuma, Y. Kato, and H. Tanaka, "Performance of combined ozonation, coagulation and ceramic membrane process for water reclamation: Effects and mechanism of ozonation on virus coagulation," Separation and Purification Technology, pp.429-434, vol. 192, 2018.

[9] L. Garcia-Cuerva,E. Z. Berglund, and A. R. Binder, "Public perceptions of water shortages, conservation behaviors, and support for 
water reuse in the U.S.," Resources, Conservation and Recycling, pp. 106-115, vol. 113, 2016.

[10] V. C. Ross, K. S. Fielding, and W. R. Louis, "Social trust, risk perceptions and public acceptance of recycled water: testing a social-psychological model," Journal of Environmental Management, pp. 61-68, vol.137, 2014.

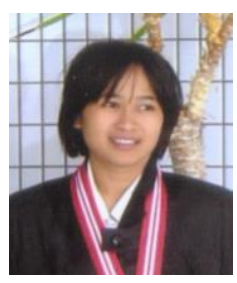

J. Yimrattanabovorn is an assistant professor at the School of Environmental Engineering, Suranaree University of Technology. She obtains her Ph.D. degree from Ehime University, Japan. Her research includes water quality, tertiary wastewater treatment and adsorption

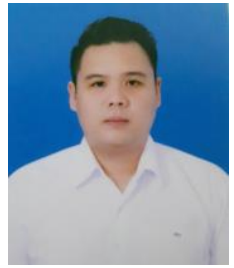

W. Wonglertarak is a doctoral student in the School of Environmental Engineering, Suranaree University of Technology (SUT). He obtains a master degree from SUT. His research includes water treatment and anaerobic digestion.

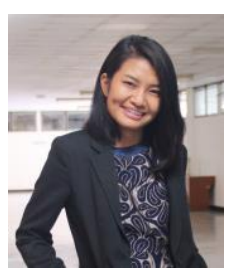

O. Rungrueang is a master student in the School of Environmental Engineering, Suranaree University of Technology (SUT). She obtains a bachelor degree from SUT. Her research includes water reclamation and Health Impact Assessment.

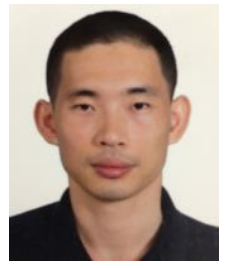

C. Hirunteeyakul is an assistant professor at the School of Civil Engineering, Suranaree University of Technology. He obtains a master degree from Khon Kaen University. His research includes water and ground water resources engineering.

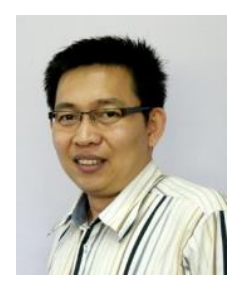

B. Wichitsathian is an associate professor at the School of Environmental Engineering, SUT. He obtains her Ph.D. degree from Asian Institute of Technology, Thailand. His research includes water quality, anaerobic digestion and membrane technology. 